\title{
The Effect of Anti-Browning Treatments for Fresh-Cut Guava Slices in Prevention of Browning during Dehydration
}

\author{
B.A.M.S.Kumara ${ }^{1 *}$, R.M.N.A.Wijewardane ${ }^{1}$ and Y.M.P. Samarasinghe ${ }^{1}$
}

Date Received: $23^{\text {rd }}$ February 2020 / Date Accepted: 22 ${ }^{\text {nd }}$ August 2020

\begin{abstract}
Purpose: Guava cultivations are spreading rapidly among Sri Lankan farmers, especially in dry zone. Surplus production is observed in certain months of the year. Dehydration can be used as an effective method to preserve the surplus. During dehydration, browning of guava impairs the quality of the final product. This experiment was carried out to find out the most effective browning inhibitor.
\end{abstract}

Research Method: Four treatments were used prior to dehydration namely, Citric acid (CA), Ascorbic acid (AA), Sodium metabisulfite (SMS) and Blanching for 2 minute in $60^{\circ} \mathrm{C}(B L)$ as twenty different combinations. The $L^{*}, a^{*}$ and $b^{*}$ values, were recorded. Colour differences with fresh slices, total colour difference (TCD) and browning index (BI) were calculated.

Findings : $L^{*}, a^{*}$ and $b^{*}$ values were significantly different $(P<0.05)$ among treatments. The lowest $L^{*}$ value difference was observed in CA $0.3 \%$ with $B L(3.18 \pm 0.7)$. Lowest total colour difference and the lowest browning index were observed in blanching treatment followed by $C A 0.3 \%$ with $B L$. Whereas the highest TCD was in control sample $(21.86 \pm 2.75)$ and the highest BI was in SMS 0.5\% with BL (55.38 \pm 8.59$)$. Results revealed that out of the treatments under study, BL only and CA $0.3 \%$ with $B L$ were the most effective solutions to overcome the browning of guava during dehydration.

Originality/Value : Research findings could be used in guava dehydration industry to preserve the colour and visual quality of the dehydrated products which will increase the consumer acceptability and demand thereby reducing postharvest losses.

Keywords: Browning, Color, Dehydration, Guava, Postharvest, Value addition

\section{INTRODUCTION}

Sri Lanka is a tropical country blessed with a high diversity of fruit crops grown naturally throughout the country. Most of them are seasonal bearers producing large amounts during the season, lowering market price. Guava (Psidium guajava L.) is popular among Sri Lankans because of its inherent flavor and eating quality. It is an excellent source of vitamin $\mathrm{C}$, containing about $17 \%$ dry matter and $80 \%$ moisture along with an appreciable amount of minerals such as phosphorus, calcium, iron, potassium, magnesium as well as vitamins like niacin, pantothenic acid, thiamin, riboflavin and vitamin A (Rana et al., 2015; Mahendran, 2010). In addition, it contains antioxidant pigments of carotenoids and polyphenols providing a high dietary antioxidant value (Ellong, 2015). Cultivated guavas produce fruits throughout the year with little seasonal effect. The Guava cultivations are spreading faster among Sri Lankan farmers especially in dry zone, who cultivate mainly "kilo pera"(Malaysian variety) in earlier days and presently, the cultivar Bangkok giant called "Apple guava". Even though majority of farmers cultivate these two cultivars, the Department of Agriculture has introduced many guava varieties

\footnotetext{
I National Institute of Post Harvest Management, Jayanthi Mawatha, Anuradhapura (50000), Sri Lanka

kbamsmahesh@gmail.com
}

iD http://orcid.org/0000-0001-5825-2313 
namely, Horana red, Horana white, Pubudu, Lanka giant, Horana sweet, Sweet giant and Hoarana rosy (DOA, 2020).

However, the market price of guava reduces considerably during the fruit season mainly because of higher production and the availability of diversity of fruits in the market leading to a lower demand. With the availability of varieties of fruits in the market, the demand for a particular fruit reduces, hence farmers suffer to sell their products during the season and surplus get wasted leading higher postharvest losses. Focusing on the value added products, is one of the major solutions to reduce the postharvest losses. However, value added products of guava is not popular among Sri Lankans, even though there are many forms of value added products available in the global markets namely; Guava puree, Jam, jelly, juice, powder, vine, bottled guava slices, dehydrated guava etc. Among the various ways and means of product processing, dehydration or drying is the most common and effective food preservation method (Kek et al., 2013). Dehydrated guava is one of the most popular products in Thailand (Duangmal and Khachonsakmetee, 2009). Even though dehydrated guava is not commonly consumed in Sri Lanka, it is being exported. Exported amount in 2017 was 2 tones and in 2018 it was 45 tones (DOA, 2019) showing an increasing trend and demand in the global scenario. However, browning of guava slices during dehydration is a major quality drawback for the mostly cultivated guava variety which is the "Apple Guava" in Sri Lanka. Color of the food commodities is generally subjected to changes when they are undergone food processing. However, color is a vital quality attribute of food products which is directly linked with the consumer attractiveness and acceptability. Therefore, the principal hypothesis of this study was to recognize if the selected treatments were effective in preserving color when dehydrating where the specific objectives were to improve the color during dehydration and to evaluate the color parameters of dehydrated guava.

\section{MATERIALS AND METHODS}

\section{Experimental Location}

The experiment was conducted in the laboratory of National Institute of Post Harvest Management, Anuradhapura. Guava cultivar "Bangkok giant" was harvested at the correct maturity stage from selected Guava cultivations in Ipalogama, Anuradhapura, Sri Lanka.

\section{Sample Preparation and Experimental Treatments}

Harvested fruits were packed in plastic crates and transported to laboratory of National Institute of Post Harvest Management. Fruits free from any visible defects were selected. Twenty treatment combinations were used with 4 treatments namely, Citric acid (CA), Ascorbic acid (AA) Sodium metabisulfite (SMS) and Water blanching for 2 minute in $60{ }^{\circ} \mathrm{C}(\mathrm{BL})$. These treatments were selected based on literature and applied as a dipping treatment for sliced guava for 10 minutes. Control is the dipping in water for 10 minutes.

The treatment combinations were,

- Blanching at $60{ }^{\circ} \mathrm{C}$ for 2 minutes

- SMS - $0.3 \%$ without blanching

- SMS -0.3\% with blanching

- SMS - $0.5 \%$ without blanching

- SMS -0.5\% with blanching

- Citric acid (CA) - 0.5\% without blanching

- Citric acid (CA) - 0.5\% with blanching

- Citric acid (CA) - 0.3\% without blanching

- Citric acid (CA) - 0.3\% with blanching

- Citric acid (CA) - 0.1\% without blanching

- Citric acid (CA) - 0.1\% with blanching

- Ascorbic acid (AA) - 0.5\% without blanching

- Ascorbic acid (AA) - 0.5\% with blanching

- Ascorbic acid (AA) - 0.3\% without blanching 
- Ascorbic acid (AA) - 0.3\% with and with blanching

- Ascorbic acid (AA) - 0.1\% without blanching

- Ascorbic acid (AA) - 0.1\% with blanching

- $\mathrm{AA}-0.3 \%$ with $\mathrm{CA}-0.3 \%$

- $\mathrm{AA}-0.1 \%$ with CA - $0.5 \%$

- AA - $0.5 \%$ with CA - $0.5 \%$

From above combinations, five were selected based on visual color for further analysis after dehydration. The selected treatment combinations were,

- Blanching at $60^{\circ} \mathrm{C}$ for 2 minutes (BL)

- Citric acid (CA) - 0.3\% with BL

- Citric acid (CA) $-0.5 \%$ with BL

- Ascorbic acid (AA) - 0.5\% with BL

- SMS $-0.5 \%$ with BL

Selected fresh fruits were cut into slices $(5-8 \mathrm{~mm}$ thickness) and then the above treatments were applied following dehydration. Dehydration was done in hot air oven dryer at $60{ }^{\circ} \mathrm{C}$ for 24 hours. Color values were measured using Hunter lab color difference meter (CR 400, Konica Minolta), the values of $\mathrm{L}^{*}, \mathrm{a}^{*}$ and $\mathrm{b}^{*}$ were recorded (McGuire, 1992). Eight dehydrated samples (as replicates) were used for each treatment where colour values from 3 points were taken per replicate and averaged them. Color differences of $\mathrm{L}^{*}, \mathrm{a}^{*}$ and $\mathrm{b}^{*}$ were calculated with the fresh slices. Total colour difference was calculated using the formula given by Maskan (2001); Saricoban and Yilmaz (2010). The formula is

$$
\Delta E=\left(\left(\mathrm{L}_{0}-\mathrm{L}\right)^{2}+\left(\mathrm{a}_{0}-\mathrm{a}\right)^{2}+\left(\mathrm{b}_{0}-\mathrm{b}\right)^{2}\right)^{1 / 2}
$$

$* \Delta \mathrm{E}=$ Total color difference, $\mathrm{L}_{\mathrm{o}}=\mathrm{L}^{*}$ value of fresh sample, $L=L^{*}$ value of treated sample, $a_{0}=a^{*}$ value of fresh sample, $a=a^{*}$ value of treated sample, $b_{o}=b^{*}$ value of fresh sample, $b=$ $b^{*}$ value of treated sample

Browning index was calculated based on the formula used by Maskan (2001); Saricoban and Yilmaz (2010); Kasim and Kasim (2015). Used formula was,

$$
\begin{aligned}
& B I=\frac{[(x-0.31)]}{0.17} \\
& x=\frac{(a+1.7 L)}{(5.645 L+a-3.012 b)}
\end{aligned}
$$

Where,

The experiment was conducted as a complete randomized design. The data were analyzed using analysis of variance and means were separated using Duncan's multiple range test at $\mathrm{P}<0.05$ with SPSS statistical software 20.0.

\section{RESULTS AND DISCUSSION}

Fruits dried using hot air in conventional tray, cabinet or vacuum dryers show poor product quality, and hence less acceptance by the consumers (Jain et al., 2011). Basically when fruits are undergone to dehydration processes, color change is a common scenario which reduces the consumer preference and it has a greater impact on marketability of the product. Hence color should be preserved to increase the consumer acceptability.

Results of the present study revealed that the browning reaction was occurred during the dehydration process whereas any color change was not observed in fresh cuts (without any treatment) even after $24 \mathrm{~h}$ of storage. Hence, it should not be the enzymatic browning. Changes of $\mathrm{L}^{*}, \mathrm{a}^{*}$ and $\mathrm{b}^{*}$ color values were observed differently with different treatments (Table 01).

The $\mathrm{L}^{*}$ coordinate indicates darkness or lightness of color and ranges from black (0) to white (100). Coordinates of $a^{*}$ and $b^{*}$ indicate the color directions. Negative $a^{*}$ values indicate the greenness whereas positive values indicate redness. Negative $b^{*}$ values indicate the blueness and positive values indicate the yellowness (McGuire, 1992). 
Table 01: Color values of $L^{*}, a^{*}$ and $b^{*}$ of fresh and dehydrated guava samples with different treatments

\begin{tabular}{cccccccc}
\hline Color & Fresh & Control & BL & CA_0.3\%+ & CA_0.5\% & AA_0.5\%+ & SMS_0.5\%+ \\
& & & & BL & + BL & BL & BL \\
\hline L $^{*}$ & $85.74 \pm 1.3^{\mathrm{a}}$ & $67.91 \pm 4.1^{\mathrm{e}}$ & $80.59 \pm 5.9^{\mathrm{b}}$ & $83.16 \pm 1.7^{\mathrm{ab}}$ & $78.12 \pm 3.9^{\mathrm{c}}$ & $73.87 \pm 3.1^{\mathrm{d}}$ & $75.21 \pm 3.7^{\mathrm{cd}}$ \\
$\mathrm{a}^{*}$ & $-3.22 \pm 1.2^{\mathrm{a}}$ & $3.27 \pm 1.4^{\mathrm{e}}$ & $0.32 \pm 1.1^{\mathrm{b}}$ & $0.46 \pm 0.7^{\mathrm{bc}}$ & $1.43 \pm 0.7^{\mathrm{cd}}$ & $4.11 \pm 0.8^{\mathrm{e}}$ & $1.69 \pm 0.8^{\mathrm{d}}$ \\
$\mathrm{b}^{*}$ & $13.67 \pm 2.7^{\mathrm{a}}$ & $24.70 \pm 3.5^{\mathrm{bc}}$ & $23.50 \pm 3.3^{\mathrm{b}}$ & $27.14 \pm 1.2^{\mathrm{c}}$ & $30.99 \pm 3.1^{\mathrm{d}}$ & $24.98 \pm 3.2^{\mathrm{bc}}$ & $32.20 \pm 4.3^{\mathrm{d}}$ \\
\hline
\end{tabular}

Each value represents \pm S.D. of eight replicates. Values in the same row with different superscript letters differ significantly (P<0.05). $L^{*}$ - lightness, $a^{*}$-green to red., $b^{*}$-yellow to blue. $B L=$ Blanching at $60^{\circ} \mathrm{C}$ for 2 minutes, $C A=C i t r i c$ acid, $A A=A s c o r b i c$ acid, $S M S=$ Sodium metabisulfite.

Guava fruits change their color into a greater extent when dehydrating (Table 01) where the results of the study revealed that the $\mathrm{L}^{*}$ value of the guava samples decreased significantly $(\mathrm{P}<0.05)$ after dehydration. The highest lightness (L* value) was observed in fresh samples whereas the lowest in control sample (Table 01) indicating the considerable color change. Reduction of $\mathrm{L}^{*}$ value indicates that the browning takes place during the dehydration leading to discolored final product. Reduction of $\mathrm{L}^{*}$ value was also observed by Damasceno et al. (2008) for cashew apple juice when undergone higher temperature treatments showing non enzymatic browning. According to the results of the present study (Table 02 ), the lowest $\mathrm{L}^{*}$ value difference (LD) was observed in CA treated guava samples for 10 minutes with the concentration of $0.3 \%$ combined with BL. The second lowest LD was observed with the samples undergone blanching treatment (Table 02). There was no significant difference $(\mathrm{P}>0.05)$ observed between these two treatments whereas significant difference
$(\mathrm{P}<0.05)$ was observed with other treatments for LD.

Fresh guava samples attained the lowest a* value while AA $0.5 \%$ with BL treated sample showed the highest followed by the control samples (Table 01). Color values of a* were significantly different $(\mathrm{P}<0.05)$ among all the treatments except for $\mathrm{CA} 0.3 \%$ with $\mathrm{BL}$ and the blanching treatment for 2 minutes at $60^{\circ} \mathrm{C}$. The lowest difference of $\mathrm{a}^{*}$ value with fresh sample was observed in blanching treatment followed by CA $0.3 \%$ with BL (Table 02).

The lowest $b^{*}$ value was obtained by fresh guava samples while the highest was in SMS 0.5\% with BL followed by CA $0.5 \%$ with BL (Table $01)$. Blanching treatment for 2 minutes with 60 ${ }^{\circ} \mathrm{C}$ was exhibited the lowest $\mathrm{b}^{*}$ value difference compared with the fresh samples (Table 02) maintaining $b^{*}$ value nearest to the fresh samples showing lesser color change.

Table 02: Differences of $L^{*}, a^{*}$ and $b^{*}$ color values of dehydrated guava samples in different treatments compared with fresh sample

\begin{tabular}{ccccccc}
\hline Color & Control & BL & $\begin{array}{c}\text { CA_0.3\%+ } \\
\text { BL }\end{array}$ & $\begin{array}{c}\text { CA_0.5\% } \\
+ \text { BL }\end{array}$ & $\begin{array}{c}\text { AA_0.5\%+ } \\
\text { BL }\end{array}$ & \multicolumn{1}{c}{ SMS_0.5\%+ } \\
\hline L $^{*}$ & $18.23 \pm 2.7^{\mathrm{d}}$ & $4.37 \pm 2.7^{\mathrm{a}}$ & $3.18 \pm 0.7^{\mathrm{a}}$ & $8.22 \pm 2.7^{\mathrm{b}}$ & $12.27 \pm 1.6^{\mathrm{c}}$ & $10.93 \pm 2.1^{\mathrm{c}}$ \\
$\mathrm{a}^{*}$ & $6.50 \pm 1.1^{\mathrm{b}}$ & $3.54 \pm 1.5^{\mathrm{a}}$ & $3.68 \pm 1.5^{\mathrm{a}}$ & $4.65 \pm 1.5^{\mathrm{a}}$ & $7.34 \pm 1.3^{\mathrm{b}}$ & $4.91 \pm 1.3^{\mathrm{a}}$ \\
$\mathrm{b}^{*}$ & $11.04 \pm 1.6^{\mathrm{a}}$ & $9.83 \pm 5.1^{\mathrm{a}}$ & $13.48 \pm 3.2^{\mathrm{ab}}$ & $17.32 \pm 3.8^{\mathrm{bc}}$ & $11.31 \pm 4.3^{\mathrm{a}}$ & $18.53 \pm 5.4^{\mathrm{c}}$ \\
\hline
\end{tabular}

Each value represents \pm S.D. of eight replicates. Values in the same row with different superscript letters differ significantly $(P<0.05)$. $L^{*}$ - lightness, $a^{*}$-green to red., $b^{*}$-yellow to blue. $B L=B l a n c h i n g$ at $60^{\circ} \mathrm{C}$ for 2 minutes, $C A=C i t r i c$ acid, $A A=A s c o r b i c$ acid, $S M S=$ Sodium metabisulfite. 
It is quite difficult to select a treatment which shows the lowest color difference by comparing $\mathrm{L}^{*}, \mathrm{a}^{*}$ and $\mathrm{b}^{*}$ color values separately because their behavior was different in different treatments (table 1,2). Therefore, it is important to focus on the total color difference which gives an overall value of color change. Results of the present study shows that the lowest total color difference was obtained from BL treatment followed by CA $0.3 \%$ treatment combined with BL (Table 03). And the statistical analysis showed that there was no significant difference $(\mathrm{P}>0.05)$ between these two treatments while significant difference $(\mathrm{P}<0.05)$ was observed with other treatments.

Because of the brown color of the final product caused by browning reactions, it is important to focus on browning index when selecting an effective browning inhibitor while focusing on color changes and color differences. The highest browning index showed the highest brown color whereas the lowest browning index gives the lowest brown color of the final product. According to the results, the lowest browning index was reported from the samples undergone BL treatment followed by CA $0.3 \%$ treatment combined with BL (Table 03) where no significant difference $(\mathrm{P}>0.05)$ was observed between these two treatments.

Ascorbic acid acts as an antioxidant and is naturally present in fresh fruits and vegetables (kabasakalis et al., 2000). Citric acid is more predominantly present in berries, citrus and tropical fruits (del Campo et al., 2006). Hence these two chemical compounds are consumed daily by majority of the people where it is safe to use as treatments in food industry. Apart from that sodium metabisulfite is a commonly used chemical compound to prevent enzymatic and non-enzymatic browning of fruits and vegetables (Molnar-Perl and Friedman, 1990; Lim and Wong, 2018). Citric acid, ascorbic acid and sulfites are considered as effective treatments in controlling browning (Garcia and Barrett, 2002; Cortez-Vega et al., 2008; Suttirak and Manurakchinakorn, 2010).

Even though ascorbic acid and SMS considered as effective browning inhibiters, results of the present study showed that they were not effective in controlling browning of guava when dehydrating even with the combination with hot water blanching. Contrary to the results of the present study, SMS was given promising results to prevent color changes of dried chili and apple (Chaethongnand and Pongsawatmanit, 2015; Cortez-Vega et al., 2008). Ascorbic acid aggravated browning and SMS increased the $b^{*}$ value which indicates the increment of yellow color in dehydrated guava samples. Ascorbic acid induced browning reactions may be occurred during the dehydration which may be the reason for increment of browning in ascorbic acid treated guava samples (Bradshaw et al., 2001). Cortez-Vega et al. (2008) also revealed that the ascorbic acid was not much effective in controlling the browning of minimally processed apple compared with SMS treatment. Contrary to that, ascorbic acid and SMS were effective in controlling the browning of green coconut water when subjected to thermal processing where the effectiveness of SMS was higher than ascorbic acid even though both were effective (Tan et al., 2015). Furthermore, 1\% (w/v) Ascorbic acid was more effective in preventing browning of Golden Delicious and Elstar apple varieties (Shrestha et al., 2020). However, according to the results of the present study, ascorbic acid individually or combined with hot water blanching was not much effective in controlling browning of guava when dehydrating.

CA_0.3\%+ BL was given promising results compared with AA_0.5\%+ BL, SMS_0.5\%+ BL and SMS_0.5\%+ BL treatments in the present study. These results revealed that the minor concentration of citric acid combined with blanching was effective in controlling browning of guava during dehydration. In previous studies, the effect of citric acid in prevention of browning was investigated and promising results were obtained for banana slices (Moline et al., 1999). Furthermore, Suttirak and Manurakchinakorn (2010) revealed that the Citric acid is more effective in prevention of browning when combined with other anti-browning agents like Ascorbic acid even though it was not success in present study. Citric acid was more effective in present study when it was used as a combination with blanching. 
Table 03: Total color difference and browning index of dehydrated guava samples with different treatments.

\begin{tabular}{lcc}
\hline \multicolumn{1}{c}{ Treatment } & TCD & BI \\
\hline Control & $21.86 \pm 2.75^{\mathrm{a}}$ & $47.86 \pm 10.04^{\mathrm{a}}$ \\
BL & $12.50 \pm 3.12^{\mathrm{b}}$ & $33.35 \pm 4.88^{\mathrm{b}}$ \\
CA_0.3\%+BL & $14.45 \pm 3.01^{\mathrm{b}}$ & $38.91 \pm 2.32^{\mathrm{bc}}$ \\
CA_0.5\%+BL & $20.15 \pm 2.70^{\mathrm{ac}}$ & $50.74 \pm 7.55^{\mathrm{ad}}$ \\
AA_0.5\%+BL & $18.39 \pm 2.46^{\mathrm{c}}$ & $44.23 \pm 6.31^{\mathrm{ac}}$ \\
SMS_0.5\%+BL & $22.20 \pm 3.85^{\mathrm{a}}$ & $55.38 \pm 8.59^{\mathrm{d}}$ \\
\hline
\end{tabular}

Each value represents \pm S.D. of eight replicates. Values in the same column with different superscript letters differ significantly $(P<0.05)$. TCD=Total color difference, BI=Browning index. BL=Blanching at $60^{\circ} \mathrm{C}$ for 2 minutes, CA=Citric acid, AA=Ascorbic acid, $S M S=$ Sodium metabisulfite

Blanching treatment for 2 minutes in $60^{\circ} \mathrm{C}$ showed positive results towards the reduction of color change in dehydrated guava samples. This may be due to inhibition or deactivation of the compounds which are responsible for the browning reaction of Guava. Blanching was used to get effective results for mango and Indian gooseberry as well in preventing browning in previous studies (Ndiaye, Xu \& Wang, 2009; Gudapaty et al., 2010). In addition to that the best results were obtained with blanching treatment for Japanese quince fruits when they produce dehydrated candied (Krasnova et al., 2018). Positive results of blanching were obtained for salak fruit dehydration where effectively minimized browning during dehydration and appreciable color change was observed during storage (Ong and Law, 2011). Furthermore, the effectiveness of hot water blanching combination with Citric acid was observed for some apple varieties (Shrestha et al., 2020).

Considering all the color values with the tested treatment combinations, it was revealed that the lowest color change was observed in blanching treatment at $60{ }^{\circ} \mathrm{C}$ for 2 minutes followed by the CA $0.3 \%$ with BL treatment. However, the effectiveness on browning prevention is mainly dependent on the produce types and cultivars, and concentrations of anti-browning agents (Suttirak and Manurakchinakorn, 2010).

However, the browning process for the cultivar 'Apple Guava' should be studied further to clarify and to deeply understand the type of browning occurred, where the present study was mainly aimed at identifying the effective browning inhibitors during dehydration rather than focusing on the type of browning.

\section{CONCLUSIONS}

Experimental results showed that, the blanching at $60{ }^{\circ} \mathrm{C}$ for 2 minutes was more effective in controlling the browning of guava during dehydration. However, citric acid $0.3 \%$ combined with blanching treatment was also effective in controlling the browning of guava when dehydrating. Even though these two treatments effectively inhibit the browning, the water blanching treatment $\left(60^{\circ} \mathrm{C}\right.$ for 2 minutes $)$ is more suitable to use in the industry as it reduces the cost for the treatments.

\section{Conflict of Interest}

The authors declare that there is no conflict of interest. 


\section{REFERENCES}

Bradshaw, M.P., Prenzler, P.D. and Scollary, G.R. (2001). Ascorbic acid-induced browning of $(+)$-catechin in a model wine system. Journal of agricultural and food chemistry. 49(2):934939. https://doi.org/10.1021/jf000782f

Chaethong, K. and Pongsawatmanit, R. (2015). Influence of sodium metabisulfite and citric acid in soaking process after blanching on quality and storage stability of dried chili. Journal of food processing and preservation. 39(6):2161-2170. https://doi.org/10.1111/jfpp.12460

Cortez-Vega, W.R., Becerra-Prado, A.M., Soares, J.M. and Fonseca, G.G. (2008). Effect of L-ascorbic acid and sodium metabisulfite in the inhibition of the enzymatic browning of minimally processed apple. International Journal of Agricultural Research. 3(3):196-201. https://doi. org/10.3923/ijar.2008.196.201

Damasceno, L.F., Fernandes, F.A., Magalhães, M.M. and Brito, E.S. (2008). Non-enzymatic browning in clarified cashew apple juice during thermal treatment: Kinetics and process control. Food Chemistry. 106(1): 172-179. https://doi.org/10.1016/j.foodchem.2007.05.063

Duangmal, K. and Khachonsakmetee, S. (2009). Osmotic dehydration of guava: influence of replacing sodium metabisulphite with honey on quality. International journal of food science \& technology. 44(10):1887-1894. https://doi.org/10.1111/j.1365-2621.2008.01906.x

del Campo, G., Berregi, I., Caracena, R. and Santos, J.I. (2006). Quantitative analysis of malic and citric acids in fruit juices using proton nuclear magnetic resonance spectroscopy. Analytica Chimica Acta 556(2):462-468. https://doi.org/10.1016/j.aca.2005.09.039

Department of Agriculture, Sri Lanka (2020). https://doa.gov.lk/FCRDC/index.php/en/2015-09-2205-59-42/33-guava1 28.01.2020

Department of Agriculture, Sri Lanka (2019). https://www.doa.gov.lk/ICC/images/publication/ Books/Other_Bok/AgstatBK.pdf 28.01.2020

Ellong, E.N., Billard, C., Adenet, S. and Rochefort, K., 2015. Polyphenols, carotenoids, vitamin C content in tropical fruits and vegetables and impact of processing methods. Food and Nutrition Sciences. 6(03):299. doi:10.4236/fns.2015.63030

Garcia, E. and Barrett, D.M. (2002). Preservative treatments for fresh-cut fruits and vegetables. Freshcut fruits and vegetables.267-304. https://ucanr.edu/sites/zann_test/files/28711.pdf 29.08.2019. https://doi.org/10.1201/9781420031874.ch9

Gudapaty, P., Indavarapu, S., Korwar, G.R., Shankar, A.K., Adake, R.K.V., Bandi, V. and Kanchu, S.R. (2010). Effect of open air drying, LPG based drier and pretreatments on the quality of Indian gooseberry (aonla). Journal of food science and technology. 47(5): 541-548. doi:10.1007/ s13197-010-0093-2

Jain, S.K., Verma, R.C., Murdia, L.K., Jain, H.K. and Sharma, G.P. (2011). Optimization of process parameters for osmotic dehydration of papaya cubes. Journal of food science and technology. 48(2): 211-217. https://doi.org/10.1007/s13197-010-0161-7

Kabasakalis, V., Siopidou, D. and Moshatou, E. (2000). Ascorbic acid content of commercial fruit juices and its rate of loss upon storage. Food chemistry. 70(3): 325-328. https://doi. org/10.1016/s0308-8146(00)00093-5 
Kasim, R. and Kasim, M.U. (2015). Biochemical changes and color properties of fresh-cut green bean (Phaseolus vulgaris L. cv. gina) treated with calcium chloride during storage. Food Science and Technology. 35(2): 266-272. https://doi.org/10.1590/1678-457x.6523

Kek, S.P., Chin, N.L. and Yusof, Y.A. (2013). Direct and indirect power ultrasound assisted pre-osmotic treatments in convective drying of guava slices. Food and Bioproducts Processing, 91(4): 495506. https://doi.org/10.1016/j.fbp.2013.05.003

Krasnova, I., Seglina, D. and Pole, V. (2018). The effect of pre-treatment methods on the quality of dehydrated candied Japanese quince fruits during storage. Journal of food science and technology. 55(11): 4468-4476. https://doi.org/10.1007/s13197-018-3375-8

Lim, W.Y. and Wong, C.W. (2018). Inhibitory effect of chemical and natural anti-browning agents on polyphenol oxidase from ginger (Zingiber officinale Roscoe). Journal of food science and technology. 55(8): 3001-3007. https://doi.org/10.1007/s13197-018-3218-7

Mahendran, T. (2011). Physico-chemical properties and sensory characteristics of dehydrated guava concentrate: effect of drying method and maltodextrin concentration. Tropical Agricultural Research and Extension. 13(2): 48-54. https://doi.org/10.4038/tare.v13i2.3138

Maskan, M. (2001). Kinetics of colour change of kiwifruits during hot air and microwave drying. Journal of food engineering. 48(2): 169-175. doi:10.1016/s0260-8774(00)00154-0

McGuire, R.G. (1992). Reporting of objective color measurements. HortScience. 27(12): 1254-1255. https://doi.org/10.21273/hortsci.27.12.1254

Moline, H.E., Buta, J.G. and Newman, I.M. (1999). Prevention of browning of banana slices using natural products and their derivatives 1. Journal of Food Quality. 22(5): 499-511. https://doi. $\operatorname{org} / 10.1111 / \mathrm{j} .1745-4557.1999 . t b 00181 . x$

Molnar-Perl, I. and Friedman, M. (1990). Inhibition of browning by sulfur amino acids. 3. Apples and potatoes. Journal of Agricultural and Food Chemistry. 38(8): 1652-1656. https://doi. org/10.1021/jf00098a006

Ndiaye, C., Xu, S.Y. and Wang, Z. (2009). Steam blanching effect on polyphenoloxidase, peroxidase and colour of mango (Mangifera indica L.) slices. Food Chemistry. 113(1): 92-95. doi:10.1016/j. foodchem.2008.07.027

Ong, S.P. and Law, C.L. (2011). Microstructure and optical properties of salak fruit under different drying and pretreatment conditions. Drying technology. 29(16): 1954-1962. https://doi.org/10. 1080/07373937.2011.606389

Rana, S., Siddiqui, S. and Goyal, A. (2015). Extension of the shelf life of guava by individual packaging with cling and shrink films. Journal of food science and technology. 52(12): 81488155. https://doi.org/10.1007/s13197-015-1881-5

Saricoban, C. and Yilmaz, M.T. (2010). Modelling the effects of processing factors on the changes in colour parameters of cooked meatballs using response surface methodology. World Applied Sciences Journal. 9(1): 14-22.

Suttirak, W. and Manurakchinakorn, S. (2010). Potential application of ascorbic acid, citric acid and oxalic acid for browning inhibition in fresh-cut fruits and vegetables. Walailak Journal of Science and Technology (WJST). 7(1): 5-14. 
Shrestha, L., Kulig, B., Moscetti, R., Massantini, R., Pawelzik, E., Hensel, O. and Sturm, B. (2020). Optimisation of Physical and Chemical Treatments to Control Browning Development and Enzymatic Activity on Fresh-cut Apple Slices. Foods. 9(1): 76-97 https://doi.org/10.3390/ foods 9010076

Tan, T.C., Cheng, L.H., Bhat, R., Rusul, G. and Easa, A.M. (2015). Effectiveness of ascorbic acid and sodium metabisulfite as anti-browning agent and antioxidant on green coconut water (Cocos nucifera) subjected to elevated thermal processing. International Food Research Journal. 22(2):631-637 